\title{
Contingent Crop Planning in Flood and Dry Spell of Monsoon in Bihar, India
}

\author{
Sunil Kumar ${ }^{1 *}$, Sanjay Kumar and Mishra BB ${ }^{2}$ \\ ${ }^{1}$ Department of Agronomy, India \\ ${ }^{2}$ Principal, Bihar Agricultural College, India \\ *Corresponding author: Sunil Kumar, Department of Agronomy, India
}

Submission: 眥 July 18, 2018; Published: 䟧 November 26, 2018

\begin{abstract}
Rainfall analysis for Pusa, Purnia, Sabour and Patna representing north west alluvial plains (Zone I), north east alluvial plains (Zone II) and south alluvial plains (Zone III A and III B), respectively using annual and weekly rainfall data was carried out for Bihar state. The overall mean annual rainfall was lowest (1031 mm) for zone III B and highest (1466.7 $\mathrm{mm}$ ) for zone II. But coefficient of variation was highest (30.8\%) for Pusa (zone I) and lowest $(23.7 \%)$ for Patna (zone III B). A long-term significant decreasing trend in annual rainfall was observed in Patna (zone III B). At Pusa and Purnea, $25^{\text {th }}$ to $34^{\text {th }}$ SMW are favorable weeks for field preparation/sowing and transplanting of rice crop due to more than $75 \%$ probability of rainfall of $10-30 \mathrm{~mm}$. At Sabour, probability of rainfall being more than $20 \mathrm{~mm}$ is $75 \%$ during $25^{\text {th }}-33^{\text {rd }}$ week while for Patna; it is during $27^{\text {th }}-34^{\text {th }}$ SMW. So, sowing and field operations may be delayed by two weeks in Patna region. The study revealed that crop varieties could be selected through the analysis of wet spell durations with the onset of monsoon in each region. In the flood situation, short duration rice varieties can be grown after removal of flood water. When monsoon is late or dry spell is encountered, it is wise to follow direct seeded rice or intercropping of green gram or black gram. Under stress situations, less water requirement suited crops like sorghum, ragi, finger millet and others could be adopted preferentially on land use suitability of a given soil.
\end{abstract}

\section{Introduction}

The occurrence of drought and flood is almost periodical in Bihar, where nearly $80 \%$ of annual rainfall is received in a span of four months (June-September), which is quantitatively enough for most of the crops for water. However, the aberration in temporal and spatial distribution makes the crop vulnerable to drought as well as flood [1]. Rainfall is the single most important factor in crop production planning in rainfed ecologies. The information on annual, seasonal and weekly rainfall of a region is useful to design water harvesting structure for agricultural operations, field preparation, sowing, irrigation, fertilizer application and overall in field crop planning [2]. Historically, in Bihar, zone I and zone II are receiving too much rainfall to cause flood in the region, whereas zone III B is characterized as rainfed region with low, erratic and uncertain rainfall pattern with frequent dry spells during the monsoon season. Hence, monsoon cropping is tricky operation in the region. Besides, sudden crop failures during the kharif season is a common phenomenon due to early withdrawal of monsoon. Rainfall probability pattern has been studied by many scientists in India [3] and concluded that rainfall occurrence is certain at greater than or equal to $80 \%$ probability, while $50 \%$ probability is the medium limit of certainty and may involve dry spell risk. Considering these climatic and probability factor, the study was conducted for four different locations situated in different agro climatic zones of Bihar for interlinking the rainfall probability with the crop planning pattern following the soil inherent productivity.

\section{Materials and Methods}

The weekly rainfall data for the period from 1955 to 2012 (58 years) pertaining to Pusa $\left(25^{\circ} 98^{\prime} \mathrm{N}, 8^{\circ} 13^{\prime} \mathrm{E}, 47 \mathrm{~m} \mathrm{msl}\right)$, Purnea

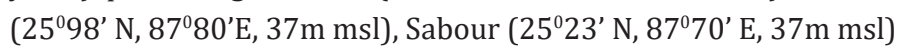
and Patna $\left(25^{\circ} 36^{\prime} \mathrm{N}, 85^{\circ} 9^{\prime} \mathrm{E}, 58 \mathrm{~m} \mathrm{msl}\right)$ representing north west alluvial plains (Zone I), north east alluvial plains (Zone II) and south alluvial plains (Zone III A and III B) of Bihar, respectively were used for analysis. Weekly, annual and seasonal rainfall distribution patterns were critically examined and analyzed. Trends were examined by Mann-Kendall rank statistics [4]. This test was used by several researchers to detect trends in hydrological time series data [5]. An initial and conditional probability of weekly rainfall at different threshold limits $(10,20 \& 30 \mathrm{~mm})$ were computed using first order Markov chain process [6]. Expected amount of rainfall at a given probability level was computed for 24-39SMW during monsoon season using Weibull's distribution [7].

\section{Results and Discussion}

\section{Variability in annual and seasonal rainfall}

The average annual rainfall of Pusa (zone I) is $1246.9 \mathrm{~mm}$ with coefficient of variation (CV) of $30.8 \%$ (Table 1). About $83.8 \%$ of annual rainfall is received from south west monsoon. The winter, pre-monsoon and post monsoon season rainfall contribute 2.4,7.9 and 5.9 percent rainfall to the annual rainfall respectively. 
For Purnea (zone II), the average annual rainfall is $1466.7 \mathrm{~mm}$ with CV $25.8 \%$. The contribution of monsoon, post monsoon, winter and pre-monsoon season rainfall to the annual rainfall is $80.1,6.5,1.4$ and 12 percent respectively. The average annual rainfall of Sabour (zone III A) is $1231.4 \mathrm{~mm}$ with CV of $24.5 \%$ and monsoon season rainfall contribution is 78.7 percent. The winter, pre-monsoon and post monsoon rainfall contribution is $2.8,10.4$ and 8.1 percent respectively. The average annual rainfall of Patna (zone IIIB) is $1031.0 \mathrm{~mm}$ with $\mathrm{CV}$ of $23.7 \%$ and monsoon season rainfall contribution is 85.9 percent. The winter, pre-monsoon and post monsoon rainfall contribution is $3.3,4.5$ and 6.3 percent respectively.

Table 1: Variation, percentage contribution (\% C) and long-term trends of seasonal and annual rainfall in four districts representing different zones of Bihar.

\begin{tabular}{|c|c|c|c|c|c|c|c|c|}
\hline \multirow[t]{2}{*}{ Season } & \multicolumn{4}{|c|}{ Pusa (zone I) } & \multicolumn{4}{|c|}{ Purnia (zone II) } \\
\hline & $\begin{array}{l}\text { Rainfall } \\
(\mathrm{mm})\end{array}$ & $\begin{array}{l}\text { CV } \\
(\%)\end{array}$ & $\% \mathrm{C}$ & $\begin{array}{l}\text { Trend } \\
\text { (mm/ } \\
\text { year) }\end{array}$ & $\begin{array}{l}\text { Rainfall } \\
\text { (mm) }\end{array}$ & $\begin{array}{l}\text { CV } \\
(\%)\end{array}$ & $\% \mathrm{C}$ & $\begin{array}{l}\text { Trend } \\
\text { (mm/ } \\
\text { year) }\end{array}$ \\
\hline Annual & 1246.9 & 30.8 & - & -1.57 & 1466.7 & 25.8 & - & 0.81 \\
\hline Winter & 30.3 & 75.8 & 2.4 & -0.48 & 20.6 & 97.5 & 1.4 & -0.1 \\
\hline Pre-monsoon & 98.6 & 59.3 & 7.9 & 1.1 & 175.5 & 54.4 & 12 & -0.14 \\
\hline Monsoon & 1044.7 & 34.3 & 83.8 & -1.2 & 1175.3 & 28.3 & 80.1 & 2.26 \\
\hline \multirow[t]{3}{*}{ Post- monsoon } & 73.3 & 93.5 & 5.9 & -0.99 & 95.4 & 99 & 6.5 & -1.2 \\
\hline & \multicolumn{4}{|c|}{ Sabour (zone III A) } & \multicolumn{4}{|c|}{ Patna (zone III B) } \\
\hline & $\begin{array}{l}\text { Rainfall } \\
\text { (mm) }\end{array}$ & $\begin{array}{l}\text { CV } \\
(\%)\end{array}$ & $\% \mathrm{C}$ & $\begin{array}{l}\text { Trend } \\
\text { (mm/ } \\
\text { year) }\end{array}$ & $\begin{array}{l}\text { Rainfall } \\
\text { (mm) }\end{array}$ & $\begin{array}{c}\text { CV } \\
(\%)\end{array}$ & $\% \mathrm{C}$ & $\begin{array}{l}\text { Trend } \\
\text { (mm/ } \\
\text { year) }\end{array}$ \\
\hline Annual & 1231.4 & 24.5 & - & 2.08 & 1031 & 23.7 & - & $-7.04 *$ \\
\hline Winter & 34.8 & 89.3 & 2.8 & -0.39 & 34 & 79.2 & 3.3 & -0.51 \\
\hline Pre-monsoon & 127.8 & 66.3 & 10.4 & 0.54 & 46.4 & 68.2 & 4.5 & $0.43^{*}$ \\
\hline Monsoon & 969.7 & 25 & 78.7 & 2.39 & 886.1 & 25.1 & 85.9 & -5.74 \\
\hline Post- monsoon & 99.1 & 91.2 & 8.1 & -0.46 & 64.5 & 94.5 & 6.3 & -1.23 \\
\hline
\end{tabular}

*Significant at $5 \%$

\section{Trend analysis}

The long-term annual rainfall of Patna (zone IIIB) shows significant decreasing trend (Table 1). In Pusa (zone I), it also shows decreasing trend but statistically non-significant. In Purnea (zone II) and Sabour (zone IIIA), there is increasing trend but statistically not significant. There is a decreasing trend of winter rainfall in all the zones though it is statistically not significant. There is significant increasing trend of pre-monsoon rainfall in Patna (zone IIIB). In pre-monsoon season, there is increasing trend of rainfall for all the zones except zone II, though it is statistically not significant. But there is decreasing trend of monsoon and post monsoon rainfall, in Pusa (zone I) and Patna (zone IIIB) though it is statistically not significant.

Table 2: Expected weekly rainfall $(\mathrm{mm})$ at different probability level (\%) in Pusa and Purne.

\begin{tabular}{|c|c|c|c|c|c|c|c|c|}
\hline \multirow{2}{*}{ SMW } & \multicolumn{9}{|c|}{ Pusa } & \multicolumn{5}{c|}{ Purnea } \\
& $50 \%$ & $75 \%$ & $90 \%$ & Total & $50 \%$ & $75 \%$ & $90 \%$ & Total \\
\hline 24 & 18.4 & 5.4 & 1.2 & 32.3 & 32 & 9.6 & 2.2 & 56.5 \\
\hline 25 & 34.4 & 10.8 & 2.7 & 58.9 & 47.5 & 24.2 & 11.6 & 59.5 \\
\hline 26 & 32 & 9.3 & 2.1 & 57.4 & 53.8 & 24.8 & 10.4 & 71.6 \\
\hline 27 & 42.9 & 16.1 & 5.1 & 65.2 & 52.8 & 21.8 & 7.9 & 75.4 \\
\hline 28 & 56.2 & 22.6 & 7.9 & 81.8 & 85.4 & 41.3 & 18.5 & 111.1 \\
\hline 29 & 50.9 & 20.3 & 7.1 & 74.2 & 82.6 & 39.8 & 17.8 & 107.5 \\
\hline 30 & 46.5 & 19.8 & 7.5 & 65 & 50.6 & 25.7 & 12.2 & 63.6 \\
\hline 31 & 42.2 & 17.8 & 6.6 & 59.3 & 53.5 & 23 & 8.8 & 74.5 \\
\hline 32 & 49.7 & 21 & 7.8 & 70 & 37.7 & 17.3 & 7.2 & 50.1 \\
\hline
\end{tabular}




\begin{tabular}{|c|c|c|c|c|c|c|c|c|}
\hline 33 & 47.5 & 19.1 & 6.7 & 69 & 42.1 & 14.4 & 4.1 & 67.8 \\
\hline 34 & 47.2 & 19.1 & 6.8 & 68.3 & 45.2 & 20.9 & 8.8 & 60 \\
\hline 35 & 33.3 & 12.6 & 4 & 50 & 34.9 & 13 & 4.1 & 53.3 \\
\hline 36 & 38.8 & 16 & 5.8 & 55.3 & 48.1 & 24.1 & 11.3 & 60.8 \\
\hline 37 & 39.4 & 15.4 & 5.2 & 58.2 & 51.2 & 22.6 & 9 & 69.9 \\
\hline 38 & 23.8 & 8.1 & 2.2 & 38.1 & 29.8 & 11.5 & 3.8 & 43.9 \\
\hline 39 & 26.1 & 6.5 & 1.2 & 51.9 & 46.7 & 17 & 5.2 & 72.4 \\
\hline
\end{tabular}

Table 3: Expected weekly rainfall ( $\mathrm{mm})$ at different probability level (\%) in Sabour and Patna.

\begin{tabular}{|c|c|c|c|c|c|c|c|c|}
\hline \multirow{2}{*}{ SMW } & \multicolumn{3}{|c|}{ Sabour } & \multicolumn{4}{c|}{ Patna } \\
\cline { 2 - 9 } & $50 \%$ & $75 \%$ & $90 \%$ & Total & $50 \%$ & $75 \%$ & $90 \%$ & 0.6 \\
\hline 24 & 22.6 & 7 & 1.7 & 38.4 & 14.7 & 3.6 & 29.6 \\
\hline 25 & 31.5 & 12.8 & 4.6 & 45.1 & 24 & 8.2 & 2.3 & 38.3 \\
\hline 26 & 39.9 & 16.8 & 6.2 & 56.2 & 31.2 & 10.3 & 2.8 & 51.2 \\
\hline 27 & 34.9 & 12.8 & 4 & 53.6 & 50.3 & 20.8 & 7.6 & 71.8 \\
\hline 28 & 54.2 & 22.3 & 8 & 77.7 & 47.6 & 17.6 & 5.5 & 73.1 \\
\hline 29 & 45.8 & 19.1 & 7 & 64.9 & 72.3 & 33.4 & 14.1 & 96.5 \\
\hline 30 & 33.1 & 12.5 & 4 & 49.7 & 49.5 & 18.2 & 5.6 & 76.2 \\
\hline 31 & 40.4 & 16.1 & 5.6 & 58.8 & 47.1 & 22.5 & 9.9 & 61.3 \\
\hline 32 & 35.9 & 13.1 & 4 & 55.3 & 49.6 & 22.8 & 9.6 & 66 \\
\hline 33 & 42.9 & 15.6 & 4.8 & 66.4 & 40.6 & 15.7 & 5.2 & 60.5 \\
\hline 34 & 26.8 & 8.8 & 2.3 & 44.1 & 55.3 & 26.2 & 11.4 & 72.5 \\
\hline 35 & 23.4 & 7.8 & 2.1 & 38 & 33.7 & 13.8 & 5 & 48 \\
\hline 36 & 25.4 & 8 & 2 & 43.2 & 36.9 & 15.8 & 6 & 51.3 \\
\hline 37 & 23.4 & 8.5 & 2.6 & 36 & 44.6 & 17.7 & 6.1 & 65.2 \\
\hline 38 & 20.4 & 5 & 0.9 & 41.4 & 16 & 5.5 & 1.5 & 25.3 \\
\hline 39 & 24 & 5.3 & 0.8 & 52.1 & 25.6 & 7.7 & 1.8 & 44.9 \\
\hline
\end{tabular}

\section{Expected rainfall amount and crop planning}

As discussed above, rainfall at $75 \%$ and $90 \%$ probability is assured rainfall and at $50 \%$ probability is the median limit for taking risk. At Pusa, the probability of more than $30 \mathrm{~mm}$ rainfall from SMW $25^{\text {th }}$ is above $50 \%$, but there is some risk. From $27^{\text {th }}$ SMW, there is probability of more than $75 \%$ of getting rainfall of more than $15 \mathrm{~mm}$ and farmers can initiate their field preparation operations and from $28^{\text {th }}$ week expected rain becomes more than $20 \mathrm{~mm}, 27^{\text {th }}$ and $28^{\text {th }}$ week are an ideal time for sowing/transplanting of kharif crop and for the crop fertilization based upon the rainfall pattern and intensity. In Purnea, the probability of more than $20 \mathrm{~mm}$ rainfall from SMW $25^{\text {th }}$ is above $75 \%$ and more than $10 \mathrm{~mm}$ rainfall is above $90 \%$ (Table 2). From SMW $25^{\text {th }}$, sowing of kharif crop can be initiated in the region. In $28^{\text {th }}$ and $29^{\text {th }}$ week probability of receiving more than $30 \mathrm{~mm}$ rainfall is more than $75 \%$ which is enough rainfall for transplanting of rice in the region. In Sabour and Patna region, the probability of more than $10 \mathrm{~mm}$ rainfall is above $75 \%$ from $25^{\text {th }}$ and $26^{\text {th }}$ SMW respectively (Table 3 ). The probability of receiving more than $20 \mathrm{~mm}$ rainfall in the regions are from $28^{\text {th }}$ and $29^{\text {th }}$ week respectively in which transplanting of rice can be completed.

\section{Contingent plan for flood affected area}

If there is total loss of rice seedlings due to flood, short duration rice var. like Prabhat, Turanta, Saket-4, Dhanlaxmi, Richhariya, Rajrndra bhagawati etc. can be sown for new seedling. By dapog method, seedlings can be making ready within 10-12 days. Already germinated seeds can be sown in the field. After flood, 50-60 days old seedlings of rice can be transplanted and at a time, 6-8 plants should be transplanted. The dose of nitrogenous fertilizer can be increased.

\section{Contingent plan for drought affected area}

Drought preventive measures: Among the different kharif crops the upland rice is most affected by drought. Therefore, diversified land use with low duty non-paddy crops is the best option in these lands. In real sense the technology available to mitigate drought are mostly preventive in nature and requires early planning. The age-old adage "Prevention is better than cure" thus holds good in drought management. Therefore, it is imperative to have a long-term policy and planning at the beginning of the season for judicious use of water, land and crops in a locality for best results. 
The major thrust in drought mitigation in rainfed areas should be on rain water management through in situ conservation and water harvesting through on-farm reservoirs/capturing runoff from local catchments/flash flood water from local streams to recycle at the time of need. Some of the important preventive measures that can be adopted early in the season to mitigate the impact of drought and augment sustainable crop production are elaborated below.

\section{Up land}

Select efficient crops and cropping systems matching the length of growing season. Some of the promising non-rice crops for rainfed uplands are maize, cowpea, arhar, blackgram, ragi, sesame, pumpkin and sweet potato. Choose short duration varieties which possess faster rate of growth, deep and penetrating root system and ability to escape drought. Store rain water to use as lifesaving irrigation. On-farm water harvesting structures lined with 6:1 soil: cement mortar of $6 \mathrm{~cm}$ thickness in $10 \%$ land area helps to harvest the rainwater for providing protective irrigation. Perform off season ploughing to conserve moisture, reduce pest and weed problem and to facilitate early sowing. Follow partial mechanization to ensure timeliness and precise of operations (desired depth and tilth) to utilize land, rainfall and other natural resources effectively. Adopt intercropping/mixed cropping system in recurrent drought prone areas as mentioned below:

The area where rainfall is between $625-850 \mathrm{~mm}$ and there is medium to deep soil and water capacity is $200-300 \mathrm{~mm}$, following intercropping system will be helpful.

Jowar+Arahar (2:1)

Maize+Soybean (1:2)

Arahar+Soybean (1:2)

Maize+Groundnut (1:3)

The area where average rainfall is more than $900 \mathrm{~mm}$ and water holding capacity of soil is $300 \mathrm{~mm}$ and there is deep soil, following intercropping can be suitable.

\section{Maize+Gram/Safflower}

Soybean-Safflower

\section{Maize-Soybean/Safflower/Gram}

In situ soil and water conservation measures like cover cropping, ridge and furrow method of planting can be done. Manage water ways through check dams, stone structures, and brushwood structures on natural streams/nallahs to store water. Water harvesting (digging ponds and lining) in 10-12\% area. Utilize harvested water through micro-irrigation methods (drip/sprinkler). Moisture conservation through mulching can be increased. Gully plugging through stacking of locally available pebbles filled in empty cement bags across water ways. Growing of grasses in water ways is also helpful in reducing soil erosion. Construct a series of percolation tanks in light textured soils to recharge the profile and for supplemental irrigation. Strengthen village institutions to enable people's participation. Apply a portion of FYM in the seed furrows at the time of sowing to conserve moisture to prevent seedling mortality from early drought. Grow short duration rice varieties such as Prabhat, Turanta, Saket-4, Dhanlaxmi, Richhariya, Rajendra bhagwati, etc. Sow non-paddy crops like ragi, maize, arhar, greengram, blackgram, cowpea, sesame, groundnut, castor in place of rice. Vegetables come up well in drought/low rainfall years. Utilize the ponds, reservoirs and water bodies for growing tomato, cauliflower, radish, brinjal, runner bean, cowpea, lady's finger and chilli.

\section{Medium/low land}

Rainwater management in medium and low lands is crucial for mitigation of drought and improvement in production. A technology for storing excess rain water in medium/low land has been standardized by devoting $10 \%$ of the cultivable area. The objective is to minimize runoff by encouraging its entry into the soil (in-situ water conservation) and capturing that which cannot get into the soil. In the first step, the field bund is strengthened by raising the dyke height to $45 \mathrm{~cm}$ with provision of weir at $20 \mathrm{~cm}$ height for spilling over excess water to runoff collection tank (refuge). The refuge is constructed at the lower reach of the plot with top width $3.0 \mathrm{~m}$, bottom width $2.0 \mathrm{~m}$ and depth $1.8 \mathrm{~m}$. The length of the refuge is equal to the width of the plot. This technology is based on the principle that out of total annual rainfall nearly $50 \%$ of the rainfall comes from a few intense showers resulting in higher runoff. On the other hand, in certain years there is a break in rainfall at a stretch for 10-12 days during crop growth period. This long stretch of dry period affects the rice crop adversely. The excess runoff discharged over the weir height during intense showers in the early season if collected in the refuge can provide protective irrigation to mitigate the intermittent drought in rice crop.

Drought ameliorative measures: It is difficult to define the exact crop and weather scenario during an anticipated drought or dry spell. Hence, it is really a difficult task to delineate rigid contingent measures well in advance of the cropping season applicable to all situations. However, there are three distinct periods of kharif season relating to crop growth stage and associated farm practices. Depending on the rainfall onset and pattern of distribution, seven types of scenarios have been projected and required contingent measures have been suggested below.

\section{Early season drought (June 10 to July 31 )}

Scenario 1: Early onset and sudden stoppage of monsoon: Under such a situation there is more likelihood of mortality of sprouts and seedlings and difficulties in sowing.

\section{Up land}

When there is more than $50 \%$ mortality, re-sow the crop up to July after receipt of enough rain water. It is always wise to raise low water requiring non-paddy crops like ragi, green gram, black gram, cowpea, sesame and castor. If mortality is less than $50 \%$, the crops may be gap filled. Cultivate vegetables-cowpea, radish, okra, cauliflower, brinjal, tomato wherever possible. 


\section{Medium and low land}

If rice population is less than $50 \%$, re-sow the crop. Select medium duration varieties. Sprouted seeds may be direct seeded or fresh seedlings of short duration varieties may be raised for transplanting. The sprouted seeds can be sown in the lines by seed drill. If the rice population is more than $50 \%$ carry out weeding and adjust the plant population by Khelua (removing and redistributing the hills) and clonal propagation. Raise community nursery of rice for transplanting at a reliable water source to save time for further delay. In saline soil use FYM/green leaf manure, sow sprouted seeds, gap fill the crop by clonal propagation.

Scenario 2: Late onset of monsoon: Sow drought tolerant nonpaddy crops like ragi, green gram, black gram, cowpea, guar, sesame, castor in place of rice. Cowpea maybe grown in the first week of August to meet the fodder crisis. Grow sweet potato in the ridges and allow the furrows to conserve rain water. Grow vegetables like tomato, cauliflower, radish, brinjal, and cowpea, lady's finger and chilly. Apply full P, K and 30\% N of the recommended dose as basal along with well decomposed organic manure for early seedling vigor. Major emphasis should be given on in-situ rain water conservation, harvesting excess run-off for its recycling to make provision for life saving irrigation.

\section{Mid-season drought (August 1 to September 15)}

Scenario 3: Non-paddy crops affected: Complete hoeing and weeding in non-paddy crop fields to provide dust mulch. Spray $2 \% \mathrm{Kcl}+0.1 \mathrm{ppm}$ boron to black gram to overcome drought situations. Foliar application of $2 \%$ urea at pre-flowering and flowering stage of green gram is helpful to mitigate drought. Spray $1 \%$ urea in brinjal. Take up spraying measures against mealy bug and mite which are more prevalent in dry weather. Top dress the crops after receipt of rain. Spray 2\% urea in late planted jute to encourage growth. Top dress nitrogen to ginger and turmeric @60 and 30kg/ha, respectively after receipt of rainfall followed by mulching. Practice mulching with organics to extend the period of moisture availability. Thin out to the extent of $25 \%$ and use the removed plants as feed/mulch. Close the drainage holes and check the seepage loss in direct sown medium land rice regularly.

Scenario 4: Beushaning of rice delayed: Do not practice beushaning (blind cultivation) in rice, if the crop is more than 45 days old. Weed out the field without waiting for rainfall. Go for gap filling using seedling of same age or clonal tillers to have a uniform distribution of plant. Strengthen the field bunds and close the holes to check seepage loss. Withhold $\mathrm{N}$ fertilizer application up to receipt of rainfall.

Scenario 5: Transplanting of rice delayed: Generally, in this case rice seedlings are over aged. Seedlings up to 45 and 60-70 days old can be transplanted in case of medium and late duration rice varieties, respectively without much reduction in yield. Remove the weeds and follow plant protection measures against blast in the nursery. Pulverize the main rice field in dry conditions, if it is not ploughed earlier to save time in final pudding. Use tractor/power tiller/tractor mounted rotavator for speedy land preparation/ puddling to cover more area with less time. Follow close transplanting using 5-7 seedlings/hill. Apply 50\% recommended nitrogen at the time of transplanting. Apply lifesaving irrigation to maintain the nursery seedlings in good health. Do not top dress nitrogen in nursery.

Scenario 6: Beushaned/transplanted rice affected at early vegetative stage: Provide protective irrigation through recycling of harvested rain water. Remove the weeds and follow plant protection measures against blast in the nursery if existing. Withhold $\mathrm{N}$ fertilizer application up to receipt of rainfall. Apply Potassic fertilizers wherever soil moisture allows or wait up to receipt of rainfall. Strengthen the field bunds and close the holes to check seepage loss.

\section{Late season drought (September 16 to October 31)}

Scenario 7: Medium and low land rice affected at vegetative/ reproductive stage: It occurs because of early cessation of monsoon rains. In this situation provide protective irrigation through recycling of harvested rain water. Provide irrigation at critical stages such as flowering, grain filling, etc. in alternate furrows in wide spaced crops. Crops like cowpea, green gram may be harvested for fodder purpose to avoid their failure as grain crops. Under situation of complete failure of kharif crop dismantle it. In such situation or where land is remaining fallow, sow (dibble) the pre-rabi crops. The ideal pre- rabi crops with residual moisture condition are horse gram, castor, niger, black gram and sesame in uplands and well drained medium lands. Pre-position inputs, particularly seeds for the rabi crop. Major crop of the region is rice, which is highly dependent on monsoon rainfall for nursery bed preparation, transplanting and maintenance of water in the field. Analysis indicates the need for selection of crops according to the probability of getting wet weeks preceded by wet weeks with the onset of southwest monsoon in the region. Timely monsoon will favour selection of long duration and high-water requiring crops like rice. Late monsoon will lead to selection of crops with medium duration and moisture stress tolerant crops like ragi, finger millet and sorghum, in the moderate rainfall districts, where erratic monsoon behavior is observed. Pulses like green gram and black gram, need to be selected often as intercropping based on varied rainfall situation. Direct seeded rice can be adopted in that situation. Analysis reveals that past rainfall record may be handy tool for future rainfall probability projections.

\section{References}

1. Ahmed P, Deka RL, Baruah BP, Nath KK (2009) Rainfall based crop planning in the Barak valley zone of Assam. J Agrometeorology 11(2): 192195.

2. Singh KA, Sikka AK, Rai S (2008) Rainfall distribution pattern and crop planning at Pusa in Bihar. J Agrometeorol 10(2): 198-203.

3. Suchit K, Behari P, Satyapriya Rai AK, Agrawal RK (2012) Long term trends in rainfall and its probability for crop planning in two districts of Bundelkhand region. J Agrometeorology 14(1): 74-78. 
4. Sneyers R (1990) On the statistical analysis of series of observation WMO Tech Note No143, Geneva, Switzerland.

5. Luo Y, Liu S, Fu S, Liu J, Wang G, et al. (2007) Trends of precipitation in Beijing river basin, Guangdong province, China. Hydrol Process 22(13): 2377-2386.
6. Robertson GW (1976) Dry and wet spells UNDP/FAO. Ton Rajak Agric, Malaysia project field report, Agro meteorological, Malaysia, p.15.

7. Chow VT (1964) Statistical and probability analysis of hydrological data. Hand book of applied Hydrology, VT chow editor, Mc Graw Hill, New York, USA, pp. 81-89.

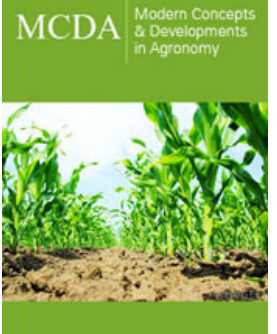

\section{Modern Concepts \& Developments in Agronomy}

\section{Benefits of Publishing with us}

- High-level peer review and editorial services

- Freely accessible online immediately upon publication

- Authors retain the copyright to their work

- Licensing it under a Creative Commons license

- Visibility through different online platforms 